\title{
SURVEYING FOURTH YEAR ENGINEERING STUDENT PERCEPTIONS OF GRADUATE ATTRIBUTE COMPETENCIES
}

\author{
Jillian Seniuk Cicek, Paul Labossiere, and Danny Mann \\ Faculty of Engineering, University of Manitoba, Winnipeg, MB, Canada R3T 5V6 \\ Corresponding author E-mail address: umseniuk@cc.umanitoba.ca
}

\begin{abstract}
As the Faculty of Engineering at the University of Manitoba begins to emphasize outcomebased teaching and assessment along with the traditional input-based teaching and assessment, data are being collected in a variety of forms. Some of the indirect data being gathered comes from students in the form of the Student Exit Survey. This survey was developed to measure students' perception of how well their program prepared them with regards to the CEAB twelve graduate attributes. The survey asked students to consider a large number of indicators for each of the graduate attributes. The indicator list was originally constructed with the intention of sufficiently defining each attribute for the five engineering programs in the faculty while providing variety and choice. Therefore, the list was fairly extensive, and at times iterative and unwieldy. When revisiting the original Student Exit Survey, two factors ascended in importance: student feedback on their personal attribute competencies as developed within their program, and how to define attribute competency levels. To establish competency levels and make indicators more manageable for faculty and students, the indicators for each attribute were revised to reflect the six levels of Bloom's Taxonomy of Educational Objectives in the Cognitive Domain: knowledge, comprehension, application, analysis, synthesis and evaluation. This new attribute/indicator format was then developed into the Student Exit Survey and given to fourth year Mechanical engineering students in Fall 2012. This paper describes that effort and analyzes the initial data from this first pass. This data will be used to inform the continued revision of the Student Exit Survey until it is a reliable and valid instrument for providing feedback at instructor, program and faculty levels as the University of Manitoba's Faculty of Engineering forges ahead with its continual cycle of improvement.
\end{abstract}

Keywords: student exit survey; graduate attribute assessment; attribute indicators; accreditation.

\section{INTRODUCTION}

As part of the accreditation process, Canadian engineering programs are required to assess students' graduate attribute competencies as designated by the
Canadian Engineering Accreditation Board (CEAB). Assessments incorporate both direct and indirect methods. Direct measures include course-based assessments of students' work, as produced traditionally in engineering through tests, exams, lab or design reports, and a variety of problem-solving, design-based assignments, as well as standardized tests [3][16]. Attribute competency levels can be nebulous and difficult to determine or conversely, complicated to link to a specific numerical or letter grade once assessments are complete. Particular aspects of an exam or assignment can be correlated to an attribute competency, but assessments require special care and attention at the outset of course development in order to target what is actually being measured [16]. To do this, graduate attribute competency indicators need first to be clearly defined.

Further to direct assessments, indirect assessments are also being gathered for accreditation. Developing a more comprehensive understanding of engineering stakeholders' perspectives is integral to the accreditation process: "A major goal in much engineering education research is to acquire a better understanding of our students, faculty, and the practicing engineering community" [9]. Surveys are a standard approach to gathering indirect data for the purposes of program assessment and improvement, and have been widely used in engineering education to gather feedback from all stakeholders [12][9][10], including graduating students' perspectives in the form of student exit surveys $[8][1][14][13]$. Although measuring perceptions has its own difficulties, for example research evidence suggests "that students and faculty often have different perceptions of educational efforts and practice" [5], perceptions "can provide an important foundation to the assessment of the success of curricular efforts" [5]. Using a student exit survey to assess students' perceived attribute competencies and program attribute strengths and weaknesses can provide additional insight and data for the graduate attribute assessment process.

\section{SURVEY DEVELOPMENT}

The Mechanical Engineering Graduate Student Exit Survey was developed to measure students' perceptions of how well their engineering program at the University of Manitoba prepared them in regard to the twelve 
graduate attributes as identified by the Canadian Engineering Accreditation Board (CEAB). The survey is based on a student exit survey created by Biosystems engineering, which was first implemented in Winter 2011 as part of BIOE 4240 Graduation Project, and was worth $5 \%$ of students' marks. This survey also comprised of the twelve CEAB graduate attributes, identified learning objectives, and an extensive list of indicators. This list was originally created by the accreditation committee struck by the Faculty of Engineering with the intent of developing a sufficient number of indicators for each of the twelve graduate attribute for all five engineering programs at the University of Manitoba, (Biosystems, Civil, Mechanical and Manufacturing, Electrical, and Computer engineering) while providing variety and choice. As a result, the list was at times iterative and unwieldy.

When revisiting the original Biosystems student exit survey, two factors ascended in importance: student feedback on their personal attribute competencies as developed within their program, and how to define attribute competency levels. In an effort to establish competency levels and make indicators more manageable for faculty and students, the indicators for each attribute were revised by Mechanical Engineering to reflect the six levels of Bloom's Taxonomy of Educational Objectives in the Cognitive Domain: knowledge, comprehension, application, analysis, synthesis and evaluation [2]. As stated by Bloom et al., "Some research workers have found the categories of use as a framework for viewing the educational process and analyzing its workings" [2]. Essentially, that is what the Cognitive Domain provided us: a framework with which to organize our attribute indicators. This is not a new idea, and has been used by other engineers/educators for a similar purpose [4][7].

This new attribute/indicator list based on Bloom's Cognitive Domain was then developed into a new student exit survey. The survey asks students to determine their own development of the twelve CEAB graduate attributes as broken down into indicators/competencies in their engineering program. A three-point scale is used to determine students' proficiency within each indicator/competency, with students asked to check whether they (i) did not develop the skill/ability; (ii) were introduced to the skill/ability; or (iii) mastered the skill/ability within the Mechanical Engineering curriculum. Figure 1 shows the instructions for the first page of the exit survey.

On the last page of the survey students are asked to rank what they consider to be their strongest/weakest attribute, as well as what they consider to be the strongest/weakest attributes in the mechanical engineering program as shown in Fig. 2. Additionally, the survey asks students to list any extra-curricular activities that they were involved with while they were in their engineering program.

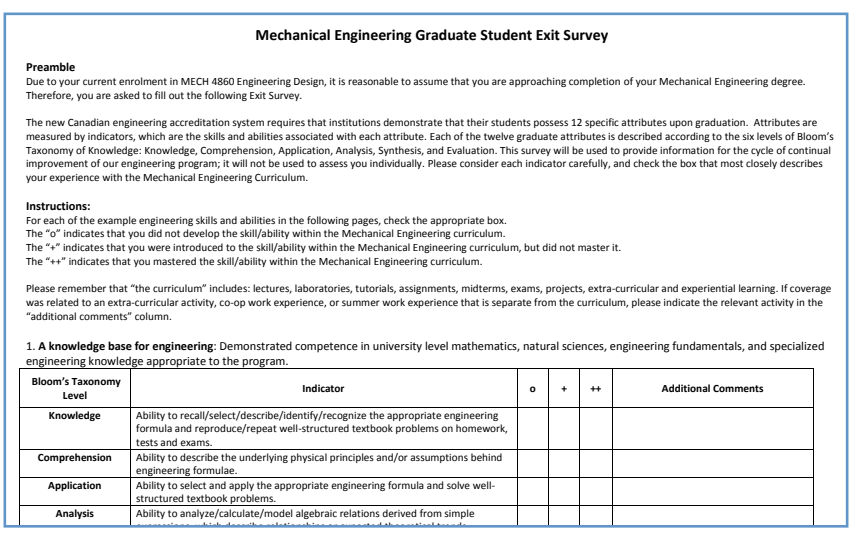

Fig. 1. First page of the Mechanical Engineering Graduate Exit Survey with instructions.

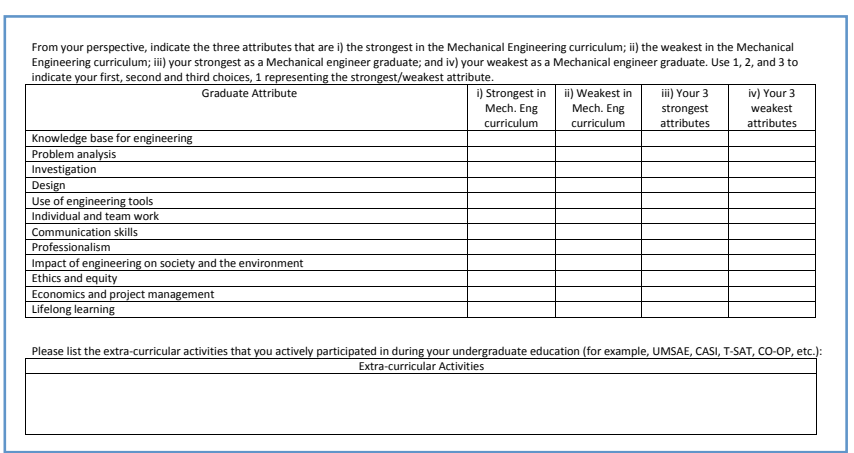

Fig. 2. Last page of the Mechanical Engineering Graduate Exit Survey with instructions for ranking attributes and listing extra-curricular activities.

\section{METHODS}

The Mechanical Engineering Graduate Student Exit Survey was administered in Fall 2012 to engineering students who were taking MECH 4860 Engineering Design. All of these students were eligible for graduation in the 2012-2013 academic year. In the course, students work on capstone design projects in teams. The instructor gave the blank surveys to the team leaders towards the end of the term; team leaders distributed the surveys to their team members outside of the class. Surveys were completed anonymously and collected by team leaders and placed into an unmarked envelop, which was sealed and returned to the instructor. No marks or other inducements were used to encourage students to fill out the surveys. Students could choose not to return the surveys. The instructor had no means of identifying which students did or did not fill out the surveys.

Surveys were analyzed once final term grades were entered and posted. Data were entered into Excel, and perceived program and student strengths and weaknesses were plotted. As well, data were plotted to explore if there was any correlation between students' extra-curricular involvement and students' attribute competency data, or 
any differences between students who self-identified as involved in extra-curricular activities compared to students who did not. Use of the data procured from the surveys for research and dissemination was approved by the governing research ethics board for the Faculty of Engineering at the $\mathrm{U}$ of $\mathrm{M}$ : Education/Nursing Research Ethics Board (ENREB).

\section{FINDINGS AND DISCUSSION}

Of the seventy-eight students from MECH 4860 Engineering Design who were given the survey, 76 students completed and returned surveys. For part 1 of the survey, numerical values were assigned to the three possible survey responses: " 3 " applied to a response indicating that the skill/ability was mastered within the curriculum, "2" applied to a response indicating that the skill/ability was not mastered within the curriculum but was introduced, and a " 1 " applied to a response indicating that the skill/ability was not developed within the curriculum. Averages were then determined for each question of the survey and are shown in Fig. 3.

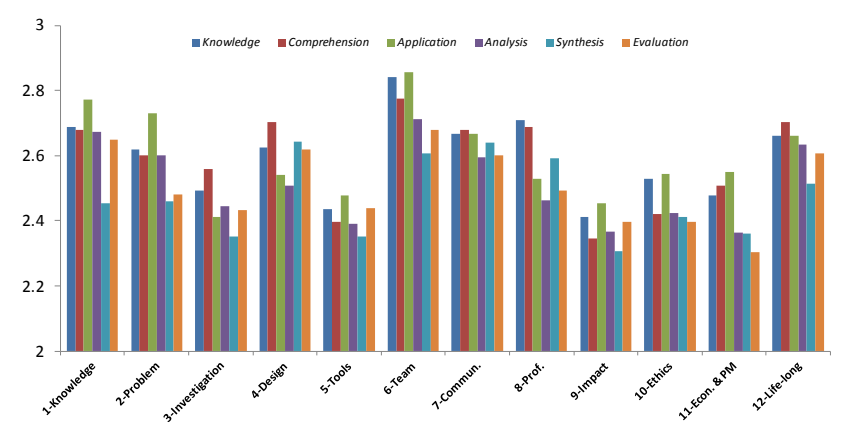

Fig. 3. Average perceived graduate competencies.

Some interesting observations are that the competency indicator application ranked highest for the attributes 1-Knowledge Base for Engineering and 2-Problem Analysis, whereas comprehension ranked highest for 3-Investigation. Analysis ranked higher for these three attributes than synthesis and evaluation. Knowledge ranked the highest for the attribute 8-Professionalism, but application and analysis were low. Application ranked the highest for attribute 10-Ethics and Equity, yet comprehension was ranked lower. Overall the averages for all attributes fell between 2.30 and 2.86, with an overall average of 2.55 , which indicates that the vast majority of students felt that all skills/abilities were introduced and that at approximately half of the students felt a level of mastery.

Averages for attributes 3-Investigation, 5-Design, 9-Impact on Society and Environment, 10-Ethics and Equity and 11-Economics and Project Management were below 2.5, signaling that most of the students felt that they were not able to master these within our curriculum; however, some indicators for these attributes did average above 2.5. Only attributes 5-Design and 9-Impact on Society and Environment did not have any indicators that rose above 2.5, with 9-Impact on Society and Environment being the lowest. Attribute 6-Individual and Team Work had the highest overall average followed by 1-Knowledge base for engineering, 7-Communication, and surprisingly, as it is often held up as an example of an attribute difficult to assess, 12-Lifelong Learning.

Figure 4 (top) shows a closer inspection of the results for what might be considered some of the "hard" skills of engineering, 1-Knowledge Base for Engineering, 2Problem Analysis, and 3-Investigation. This shows that students tended to feel more strongly about competency indicators 1 through 4: 1 Knowledge, 2-Comprehension, 3-Application and 4-Analysis, but less so about 5-Synthesis; yet there was an increase in the last competency indicator, 6-Evaluation. Original expectations were that a more consistent decrease or an obvious drop-off would be observed through the competency levels.

A look at the results as shown in Fig. 4 (bottom) for what are considered the "softer" attributes, 8Professionalism, 10-Ethics and Equity, and 12-Lifelong Learning, highlights the variability in the students' responses in regards to the competency indicators. Once again, it is surprising that lifelong learning was on average higher than the other two soft skills. Instructors have been found to struggle with assessing 12-Lifelong Learning, as it is an attribute that seems to lend itself to assessment "a priori" [15] - better measured once students are graduated and are professionally engaged. However, the data showed that students felt more proficient in these competencies than they did in 10-Ethics and Equity. In regards to this data on 10-Ethics and Equity, research suggests that there is a dearth in the teaching and assessing of ethics, and furthermore, there is a difference in perception between what faculty believe they are doing when teaching ethics, and what students regard as ethics instruction [5]. It is these differences in perceptions and surprises in the data that are worth pursuing further, and through other means, such as through focus group interviews. 

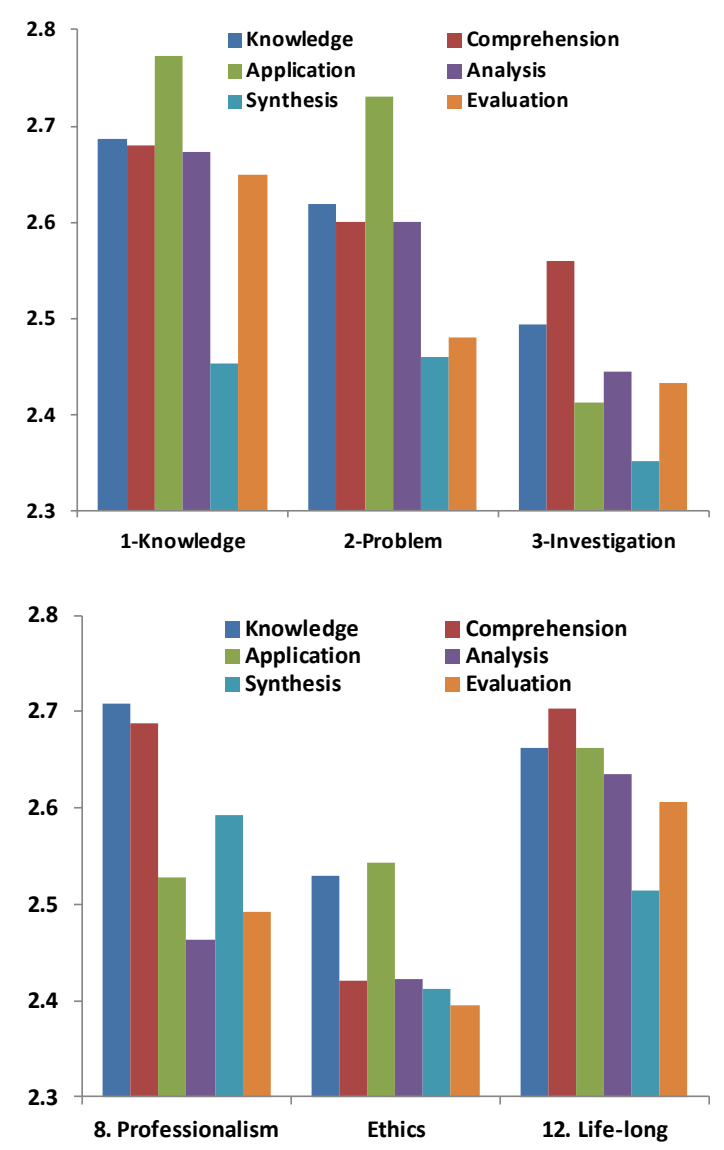

Fig. 4. Close-up view of average perceived graduate competencies for selected traditional attributes (top) and non-traditional "softer" attributes (bottom).

The results for part 2 of the survey were tabulated and Fig. 5 shows the weighted percent of responses for the top three perceived program strengths and weaknesses and student strengths and weaknesses in regards to the 12 attributes. Weighting was done based on the relative ranking of the students' perceived strengths and weaknesses. A weight of " 3 " was applied to rank of 1 , a weight of " 2 " for a rank of 2 , and a weight of " 1 " for a rank of 3. The highest ranked strengths of the program and of the students were 1-Knowledge Base for Engineering, 2-Problem Analysis, 4-Design, and 6-Individual and Team Work. The weakest for both was by far 9-Impact on Society and Environment. 10-Ethics and Equity and 11-Economics and Project Management were also significant in terms of students' perceived weakness. 7-Communication was perceived as a student strength, but not as a program strength. 8-Professionalism was not perceived as a program strength, but was not overly perceived as a program weakness. The results generally seemed to favor the "hard" skills/traditional attributes as strengths and the "soft" skills/non-traditional attributes as weaknesses; however, some of the hard skills were relatively lacking such as 5-Use of Engineering Tools, which ranked fairly high as a program weakness.

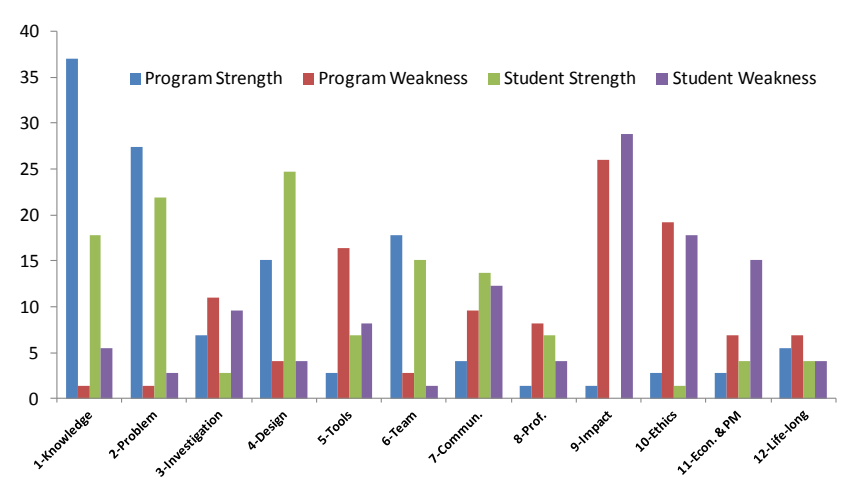

Fig. 5. Weighted percent of responses for the top three perceived program strengths and weaknesses and student strengths and weaknesses.

A comparison of percent of responses of the number one perceived program and student strength versus perceived program and student weakness shown in Fig. 6 highlights the trend of hard vs. soft skills. For the most part, high strengths were paired with low weaknesses and visaversa; however, there were exceptions: 12-Lifelong Learning, 7-Communication and 8-Professionalism were relatively neutral. Of interest is that every attribute except one was identified as being a student's top choice for either strength or weakness. The exception is that not one student identified the attribute 9-Impact on Society and Environment as their top strength; however, this attribute was still ranked second or third as a strength at least once. 

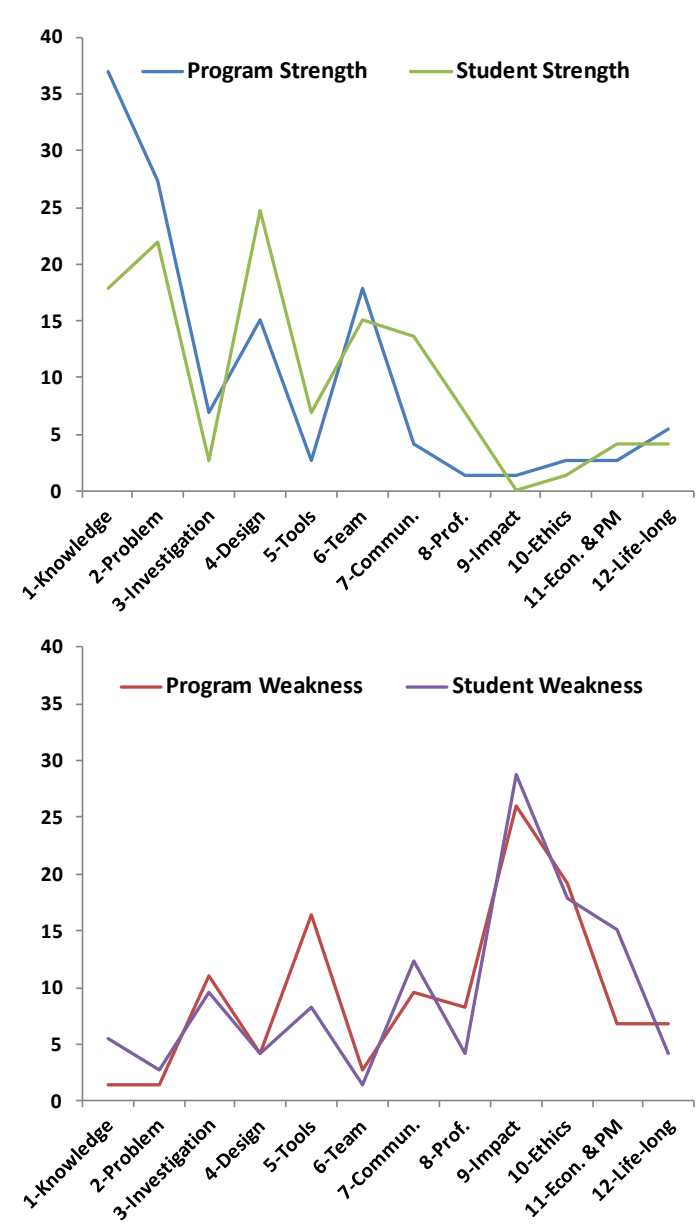

Fig. 6. Comparison of percent of responses of the number one perceived program and student strengths (top) versus perceived program and student weaknesses (bottom).

Figure 7 shows a comparison of the weighted percent of responses for the top three perceived student strengths and weaknesses with and without extra-curricular activities. Such activities were typically identified by the students as participation in student design competition teams and challenges (SAE vehicles, micro satellite, etc) and/or job experience (Co-op, part-time engineering work). The results suggest that this involvement had little effect on the student ranking of strengths and weaknesses. One exception is that students involved in extra-curricular activities ranked their weakness in 9-Impact on Society and Environment lower than student without extracurricular activities. Of interest is that although there is little difference between these two groups of students, the slight differences that do occur are not the results expected. Expectations before the survey data results were analyzed held that students with extra-curricular activities would rank attributes higher than students who did not participate in extra-curricular activities; however, results show the converse. Students' strengths without extracurricular activities for various attributes rank higher than those with extra-curricular activities in all of the soft attributes, and in several of the hard skills. Thus a comparison of the survey data raises further questions. As stated previously, focus group interviews could be guided by, and provide some insight into these trends.

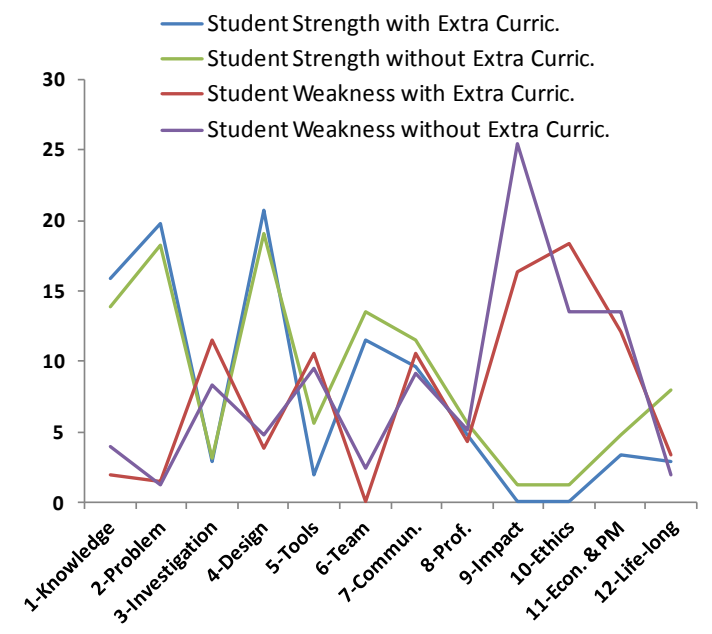

Fig. 7. Comparison weighted percent of responses of students with and without extra-curricular activities.

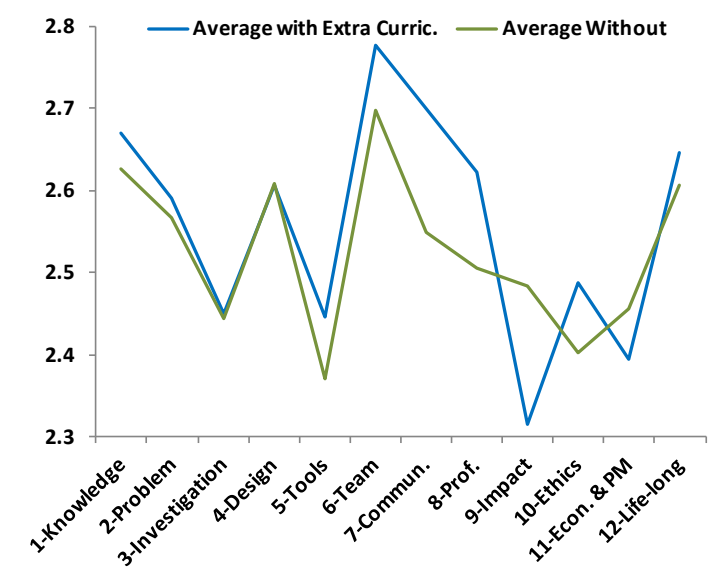

Fig. 8. Comparison of averaged perceived competencies of students with and without extra-curricular activities

Figure 8 shows a comparison of perceived competencies (from part 1 of the survey) for students with and without self-identified extra-curricular activities. The results were obtained by averaging the six competency levels, which reduces the complexity of the data. This simplification was done for illustrative purposes, although a more rigorous analysis for each competency level shows similar trends. The results show that students with extracurricular activities perceive their average competencies to be higher in 5-Use of Engineering Tools, 6-Individual and Team Work, 7-Communication, 8-Professionalism, and 10-Ethics and Equity. This is significant since one might identify these as the key 
attributes emphasized in many student design competition challenges and engineering job experience. (Surprisingly, the reverse trend is evident in Fig. 7, ranked strengths and weaknesses.) 9-Impact on Society and Environment shows the opposite behavior, where students without selfidentified extra-curricular activities perceive their competency level to be greater than those with extracurricular involvement. This perception is reflected in Fig. 7.

\section{LIMITATIONS}

Upon completion of the preliminary analysis of the results, two key limitations with the survey became apparent: 1. Failure of survey respondents to follow instructions. Failure of participants to follow instructions could indicate misunderstanding or willfulness. Examples in this survey of instructional failure include, but are not limited to (i) checkmarks on the line rather than in the box, indicating "middle ground;" (ii) missing responses; (iii) and in part 2 of the survey, multiple first place choices or simple checkmarks indicating their three strongest attributes, without ranking them. 2. Terminology used in the survey requires clarification. A second limitation resides in the construction of the survey and the terminology used. For each attribute, students were asked to determine if they (i) "did not develop the skill/ability; (ii) were introduced to the skill/ability; or (iii) mastered the skill/ability within the Mechanical Engineering curriculum." We recognize that the terminology is likely misleading. For example, "did not develop" implies a student issue/responsibility; "were introduced" implies no expectations of student performance of the skill/ability and/or no assessment by the instructor; and "mastered" implies assessment and judgment: the student is deemed to have mastery, which may indicate both instructor and student involvement/judgment. Furthermore, the term "mastery" is undefined and subject to interpretation. Do we mean mastery at the student/course/year in program level, at the new engineering graduate level, or at the experienced-inthe-field professional engineer level? And what do each of these levels look like and require in terms of a student's knowledge, skills, ability, behaviours and values? Finally, the students were provided with only three defined categories to choose from. In other words, the limitation of the three choices students were given, and the openness of the choices to interpretation by survey participants could compromise the survey's validity.

\section{NEXT STEPS}

This study represents an initial and exploratory attempt to measure our graduating engineering students' perceptions in light of the twelve CEAB graduate attributes as taught and assessed within our mechanical engineering program. We have presented preliminary results from data garnered from a student exit survey, Such an approach may be useful for identifying our students' perceptions of our program's and their attribute strengths and weaknesses; however, as shown, we are collecting perceptions, and thus there are inherent limitations. To broach these limitations, several steps have been identified. 1. This student exit survey was constructed from a revised set of attribute indicators based on Bloom's Taxonomy of Cognitive Knowledge. Input from various stakeholders, including students, alumni, faculty and engineering industry members based on qualitative methods such as focus group interviews, openended interviews and open-ended questionnaires will be used to revise and strengthen these indicators. 2. From students' tendency to mark on the line in "middle ground," and from reconsideration of the construction and terminology of our student exit survey and a look at other surveys, it is evident that our survey needs continued revision. Firstly, more choices are required for participants, and we will look at redeveloping the survey using either a 4 or 5-point Likert scale. Secondly, terminology must be commonly defined and understood by participants, and this will be achieved by conducting student and faculty focus group interviews to gather participants' interpretations and to create a common language and understanding from which to rework the survey [6][11]. We are currently in the process of organizing these focus groups in order to implement these improvements. The administration of this version of the student exit survey can be considered a pilot run. We plan to implement a cycle of discussion (focus groups) - pilot (survey) - second discussion - administration (of a revised survey) in order to strengthen our assessment instrument. (3) Finally, this survey, regardless of these approaches, will have data analysis limitations without the input of our non-student engineering stakeholders. As such, we are currently working toward the implementation of parallel surveys to be delivered to instructors, administrators and engineering industry members to measure their perceptions and provide a greater data set from which to interpret our findings and explore various perceptions. Ultimately, these steps will strengthen the validity and reliability of our student exit survey/assessment instrument.

\section{Acknowledgements}

The authors would like to thank the members of our curriculum management committee for their support and encouragement, Bernice Ezirim for assisting with data entry, and our fourth year mechanical engineering students for being willing participants in this survey. 


\section{References}

[1] J. Shawn Addington and Robert A. Johnson, "Incorporating the Design and Use of Surveys With Other Engineering Assessment Methods Under Criteria 2000 Guidelines," in Proc. ASEE American Society for Engineering Education Annual Conf., (Charlotte, NC; 20-23 June 1999), 21 pp., 1999. Retrieved from www.scopus.com

[2] Benjamin, S. Bloom (Ed.), Max D. Engelhart, Edward J. Furst, Walker H. Hill and David R. Krathwohl, Taxonomy of educational objectives: The classification of educational goals. Handbook 1: The cognitive domain. New York, NY: Longmans, Green \& Co., 1956, 207 pp.

[3] EGAD Project: Engineering Graduate Attribute Development Project, 2011. Retrieved on April 26, 2013 from http://egad.engineering.queensu.ca

[4] Jessica Harris, Alan Steele and Donald Russell, "Progress on defining the CEAB graduate attributes at Carleton University," in Proc. CEAA Canadian Engineering Education Conf., CEEC11, Andy Fisher (ed.) (St. John's, NL, 6-8 June 2011), 5 pp., 2011. Retrieved on April 26, 2013 from http://library.queensu.ca/ojs/index.php/PCEEA /article/view/3566/3581

[5] Matthew A. Holsapple, Donald D. Carpenter, Janel A. Sutkus, Cynthia J. Finelli and Trevor S. Harding, "Framing faculty and student discrepancies in engineering ethics delivery," Journal of Engineering Education, vol. 101, no. 2, pp. 169-186, 2012.

[6] Jack McGourty, Catherine Sebastian and William Swart, "Developing a comprehensive assessment program for engineering education," Journal of Engineering Education, vol. 87 , no. 4 , pp. $355-361,1998$.

[7] Mahanijah Md Kamal and Hadzli Hashim Mohd Fuad Latip, "Examinable course assessment tool based on outcome based education," in Proc. 2009 International Conference on Engineering Education, ICEED2009 - Embracing New Challenges in Engineering Education, 6 pp., 1999. Retrieved from www.scopus.com
[8] Azah H. Mohamed, Fatihah Binti Suja, \& Abdul Halim Ismail, "Graduate students' perspectives on study environment based on exit survey." Asian Social Science, vol. 8, no. 16, pp. 200-208, 2012. Retrieved from www.scopus.com

[9] Barbara M. Olds, Barbara M. Moskal and Ronald L. Miller, "Assessment in engineering education: Evolution, approaches and future collaborations," Journal of Engineering Education, vol. 94, no. 1, pp. 13-25, 2005.

[10] Richard J. Puerzer and David M. Rooney, "The alumni survey as an effective assessment tool for small engineering programs." Journal of Engineering Education, vol. 91, no. 1, pp. 109-16, 2002.

[11] Gloria M. Rogers, "EC2000 and measurement: How much precision is enough?," Journal of Engineering Education, vol. 89 , no. 2 , pp. 161-166, 2000.

[12] Scott W. Rogers and Recep K. Goktas, R, "Exploring engineering graduate student research proficiency with student surveys." Journal of Engineering Education, vol. 99, no. 3, pp. 263-278, 2010. Retrieved from www.scopus.com

[13] Susan C. Schneider and Russell J. Niederjohn, "Assessing Student Learning Outcomes Using Graduating Senior Exit Interviews and Alumni Surveys," in Proc, ASEE/IEEE American Society for Engineering Education Annual Conf., ASEE/IEEE, (Atlanta, GA; 1 -4 Nov. 1995), 5 pp., 1995. Retrieved from www.scopus.com

[14] Katherine Scales, Christi Owen, Subodh Shiohare and Michael Leonard, "Preparing for program accreditation review under ABET engineering criteria 2000: Choosing outcome indicators." Journal of Engineering Education, vol. 87, no. 3, pp. 207-210, 1998.

[15] Larry J. Shuman, Mary Besterfield-Sacre and Jack McGourty, "The ABET "professional skills" - can they be taught? Can they be assessed?" Journal of Engineering Education, vol. 94, no. 1, pp. 41-55, 2005.

[16] Neelam Soundarajan, "Preparing for accreditation under EC 2000: An experience report," Journal of Engineering Education, vol. 91, no. 1, pp. 117-123, 2002. 